\title{
A Territorial and Organizational Approach to Resilience
}

\author{
Franca Cantoni*, Paola Graziano**, \\ Fabrizio Maiocchi ${ }^{* * *}$, Paolo Rizzi ${ }^{* * * *}$
}

\begin{abstract}
Uncertainty, crisis and discontinuity induce organizations to show self-renewal and autopoietic capacity to survive and remain viable. This study is aimed at investigating the nexus eventually existing between companies' resilience and its territory. The focus of the investigation is the field of machine manufacturing and equipment and the unit of analysis are the Italian regions.
\end{abstract}

Keywords: Resilience; Organizational Capabilities; Crisis Management; Territorial Competitiveness; Global Markets

\section{Resilience: A Holistic Territorial and Organizational Approach}

Nowadays, organizations are exposed to increasingly complex and equivocal external environments characterized by hypercompetition and rapid change (Burton \& Obel, 2004). Researchers have shown a growing interest in the themes of resilient organization as an entity (Mallak, 1997; Sutcliffe \& Vogus, 2003; Sheffi, 2005; Crichton et al., 2009) and in organizational resilience as the process followed to anticipate, respond, adapt to, and/or rapidly recover from a disruptive event (Mallak, 1998; Vogus \& Sutcliffe, 2007). Some authors have highlighted its strategic aspects (Marshall \& Oijako, 2010), while others have emphasized the organizational ones (Weick \& Sutcliffe, 2011; Giustiniano \& Cantoni, 2017). Furthermore, studies tend to either diversify the static approaches from the dynamic ones (Sutcliffe \& Vogus, 2003) or to sketch new research agendas for the investigation of the organizational aspects (e.g., Hamel \& Välikangas, 2003; Vogus \& Sutcliffe, 2007; Lengnick-Hall et al., 2011). Despite the growing number of studies on resilience, and although researchers working on this theme cover different aspects, they all tend to converge on the general definition of resilience, which is the ability to find new solutions, effectively communicate them, and reorganize in response to a crisis (Kendra \& Wachtendorf, 2003; Somers, 2009).

\footnotetext{
*Associate Professor of Business Organization, Università Cattolica del Sacro Cuore (franca.cantoni@ unicatt.it) ** Professor of Regional Economics, Universidad de Cartagena (pgraziano@unicartagena.edu.co)

**** Lecturer in Accounting, Università Cattolica del Sacro Cuore (fabrizio.maiocchi@unicatt.it)

***** Associate Professor of Political Economy, Università Cattolica del Sacro Cuore (paolo.rizzi@ unicatt.it)
}

Edited by: Niccolò Cusano University

ISSN: $1593-0319$

Cantoni, F., Graziano, P., Maiocchi, F., \& Rizzi, P. (2019). A Territorial and Organizational Approach to Resilience. Symphonya. Emerging Issues in Management (symphonya.unicusano.it), 2, 109-118.

http://dx.doi.org/10.4468/2019.2.10cantoni.graziano.maiocchi.rizzi 
$\square$ More specifically, Mallak (1998) defined it as "the ability to plan and implement adaptive positive behaviors according to the specific situation", whereas Bell (2002) referred to the ability to "promptly and adequately answer to unexpected changes".

Resilience - here intended as the ability to recover from a negative and destabilizing event - is both a multifaceted and multidimensional concept (Ponomarov \& Holcomb, 2009) mainly related to the ability to endure in the face of shock/crises (resistance) and regain a new equilibrium (recovery). To create the conditions for resilience, when the probability that specific events occur is unknown and it is difficult to clearly recognize the threshold points, a detection phase of the components influencing the response capacity is desirable (Walker et al., 2004). In this regard, a holistic approach ensures an early cognitive framework of the systemic features and aspects that may affect alignment paths highlighting the contribution of all the dimensions (of the system) to the description of the phenomenon. It is a viewpoint that, in terms of descriptive completeness, aims to represent the resilience as a complex phenomenon, as multidimensional capability to determine the path of development, avoiding an underestimation of unexpected aspects (World Bank, 2014; Graziano \& Rizzi, 2016; Rizzi et al., 2017; Graziano et al., 2019). This research - starting from the assumption that both organizations and their territories are considered as systems composed of a complex network of interrelated elements - is aimed at understanding, by the use of a holistic approach, which influences there might be between an enterprise and its territory and which synergistic effects may arise from this interaction. The paper is structured in 5 blocks. After this introduction, Par. 2 will describe the aim of the research and the scope of the survey. Par. 3 is dedicated to the explanation of the methodology while in Par. 4 preliminary results will emerge. Par. 5 will be dedicated to comments and launch of the second part of the research.

\section{Aim of the Research}

The Authors consider both the territory - intended as a space where the relationships between enterprises, social groups and institutions take place - and the enterprises as organizations and therefore as interacting systems. The aim of this research is to understand what influences there may be between the companies and their territory and which synergistic effects may arise from this relationship. Specifically, it intends to investigate - on the territory defined by the Italian regions - the nexus eventually existing between company's resilience (that is the ability to withstand and recover in the face of potentially damaging exogenous events, i.e.: shocks provided by the general environment and by the task environment) and territorial resilience here represented as a measure of performance and capacity. These are two analytical approaches basically corresponding with two research streams (Foster, 2007; Rizzi et al., 2017): the first one is based on the conceptualization of resilience as a result of a path, it is an approach hazard-specific and requires the identification of the shock and recovery phases and the calculus of indicators aimed to represent the resistance during crisis and the recovery after shock (Bailey \& Turok, 2016; Martin, 2012; Martin \& Sunley, 2015). The second 
one is focused on the identification of the resources enabling a regional territory to find the proper answer to change, on the search of descriptors associated with the size of the territorial organization (Graziano, 2016). Resilience here is defined as a complex input, a multidimensional capacity determining the development of a territory (Vale \& Campanella, 2005; World Bank, 2014). The focus of the investigation is the field of machine manufacturing and equipment (ATECO sector, 28) and the unit of analysis are the Italian regions (NUTS level 2). The choice of the sector was made as functional and therefore easily associated with growing broadcast of Industry 4.0 while the level of analysis depends on the goal of the research that is the study of the interactions between enterprises, social groups and institutions, effectively captured in territorial analysis (Rizzi et al., 2012; Rizzi, 2018; Brondoni et al., 2018; Büchi et al., 2018).

Historical data series examined the period 2007-2015: data related to 2016 are excluded because of the changes in the accounting principles ${ }^{1}$ making them heterogeneous data.

The periods of crisis and recovery have been identified by observing the economic performance of machine manufacturing and equipment sector in the period 2007-2015. Figure 1 shows the dynamics of value added per capita for the 28 sector in Italy.

Figure 1: Manufacturing and Equipment Value Added per Capita in Italy (Euro)

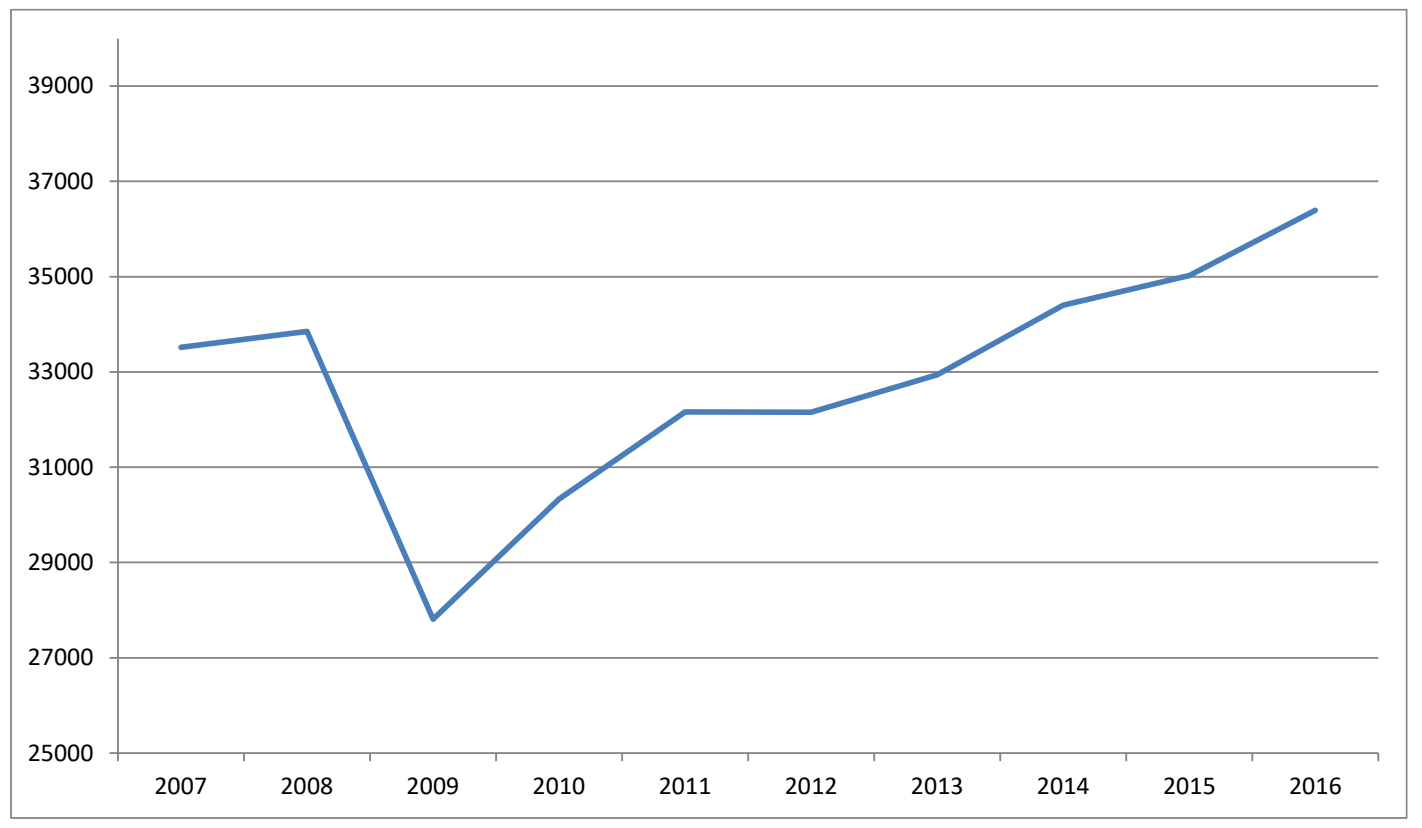

Source: Istat (2017).

The selected periods of crisis and recovery are the following ones: crisis 20072009; (first) response and recovery 2009-2011; crisis 2011-2012; (second) response and recovery 2012-2015.

To have comparable organizational structures in terms of managerial approach some choices have been made in terms of legal form: for this reason, consortia, cooperatives, small limited liability cooperative societies, limited partnership (sas), general partnership (snc), limited liability consortium, join-stock consortium were 
excluded. On the other side, the Authors decided to include: join-stock company (Spa), join-stock company (Spa) with unique member, limited liability company (srl), limited liability company ( $\mathrm{srl}$ ) with unique member as public balance sheets are settled and written by following the guidelines provided by the Civil Code.

The survey also excluded businesses with sales volume $<0$ because:

- belonging to types of entreprises such as consortia or

- of evident mistakes or misleading data in the balance sheet

- not homogeneous with the rest of the data set

and in any case not representing an interaction enterprise-market.

Also for obvious reasons, the Authors chose to process data with reference to the head and not legal office.

Finally, the shock took into account is the one associated to the economic and financial crisis. In summary, Table 1 outlines the scope of the survey:

Table 1: Scope of the Survey

\begin{tabular}{|l|l|}
\hline Territory & Italy, Regions \\
\hline Sector & C - Ateco 28 \\
\hline & - Crisis: 2007-2009 \\
Historical data & - (First) response and recovery: 2009-2011 \\
& - Crisis: 2011-2012 \\
& - (Second) response and recovery: 2012-2015 \\
\hline Legal form & Spa, Spa unique member, srl, srl unique member \\
\hline Sales volume & $>0$ \\
\hline Office & Operative (not legale) \\
\hline Shock & Exogenous crisis \\
\hline
\end{tabular}

The initial sample was composed of 20,206 enterprises while - by applying these above mentioned filters - the resulting subsample is represented by 9312 . Once agreed and shared the scope of the research, the Authors have defined the main research question as follows:

$\square$ Main RQ: By taking as unit of analysis the Italian regions (NUTS level 2) which are the (company-related/territorialrelated) determinants of the resilient performance for the field of machine manufacturing and equipment (ATECO sector, 28)?

To identify an answer to the research question described above, it is essential to understand how to measure the performance of a resilient Territorial Productive System (TPS). Hence the sub RQ turns out to be:

\section{$\square$ Sub RQ1: When a TPS can be considered as resilient?}

$\square$ Sub RQ2: How to measure the resilient performance of a TPS?

Once identified the companies and therefore the resilient territories, the research will continue with a qualitative survey aimed at understanding the determinants of the resilience of the TPS. Being this a work in progress, for the purposes of this 
work the Authors show only the first part of the research. Deliverable will be shown in the final paper.

\section{Methodology}

This research employs a quali-quantitative method of investigation.

In the first part the Authors adopt a quantitative methodology:

- to understand when a TPS can be considered as resilient and

- to position the it within a matrix (divided into 4 quadrants) expressing different levels of resistance and recovery.

To test the capacity to be resilient, we make use of the concept of solidity, which is the ability to endure independently over time coping with success to external and internal events of particular significance.

For the purpose of this research it is fundamental to understand which are the balance sheet measures that can point out the ability of an enterprise to bounce back from an external event particularly onerous as an exogenous crisis. In other words, the Authors tried to identify a magnitude of the balance-sheet which, amongst the available, should be considered as the most significant. By following its temporal dynamics their intention was to understand if the enterprise is following (or not) a path towards the return to solidity.

In this regard, the Authors agreed that EBIT - generated by the operations of the company - might be the measure to be taken as a reference as a positive Net Income can be produced only when EBIT is able to cover not only the financial costs but also the subsequent extraordinary charges ${ }^{2}$ and the tax expenses. Indeed, the primary measure less affected by financial costs, extraordinary charges and taxes and which by its nature is used to "cover" them, is the EBIT (operative income).

Getting a good level of EBIT and increasing/supporting it over time, can trigger a "virtuous" circle and consequently lead to increased solidity with obvious effects on resilience.

As the Authors consider resilience as the ability to regain a balance, EBIT is used as a measure of reference while ROS (EBIT/revenues) as a direct expression of the linkages between sales prices, volumes and operating costs given the net sales achieved.

Once defined a method for assessing the resilience of TPSs, data were aggregated per unit of analysis, that is the Italian regions (NUTS level 2).

Indicators are calculated in order to represent resistance during the crisis and recovery after recession. This measure compares the change in regional ROS with the national average change, during and after the shock (Martin, 2012), as follows:

$\beta=\frac{\left(\operatorname{ROS}_{R_{t}}-\operatorname{ROS}_{R_{t-x}}\right)-\left(\operatorname{ROS}_{N_{t}}-\operatorname{ROS}_{N_{t-x}}\right)}{\left|R O S_{N_{t}}-\operatorname{ROS}_{N_{t-x}}\right|}$

where $\operatorname{ROS}_{R}$ and $\operatorname{ROS}_{N}$ respectively represent Return on Sales at regional and national level and they are expressed as temporal variation (from $\mathrm{t}-\mathrm{x}$ to $\mathrm{t}$ ). So $\beta$ is referred to two periods of crisis and two periods of recovery. In both the cases a 
value of $\beta$ greater than 0 reveals that the performance of a specific region is better than the performance of Italy.

As anticipated, results will be made to converge in an array divided into 4 quadrants that express different level of resistance and recovery.

Once completed the first part of the survey, the second one will make use of a qualitative method to define which factors (company-related or territorial-related) have contributed to the positioning within a specific quadrant of the matrix. This paper will end with the formulation of hypotheses derived from the literature and from specific placement of some TPS within the matrix resistance/recovery.

Starting from these assumptions a questionnaire/interview will be addressed to some enterprises in the sample according to reasoned extraction criteria with the aim to identify and isolate the company-related or territorial-related determinants contributing to the positioning.

\section{Results and Comments of the Quantitative Part of the Research}

The following scatter plot (Figure 2) summarizes the relation between the measure of resistance (abscissa) and the measure of recovery (ordinate) for the Italian regions. Those measures are calculated as average between two phases of crisis (2007-2009 and 2011-2012) and the two phases of recovery (2009-2011 and 2012-2015).

Figure 2: Synthesis of the Relationship Between the Measure of Resistance and Recovery

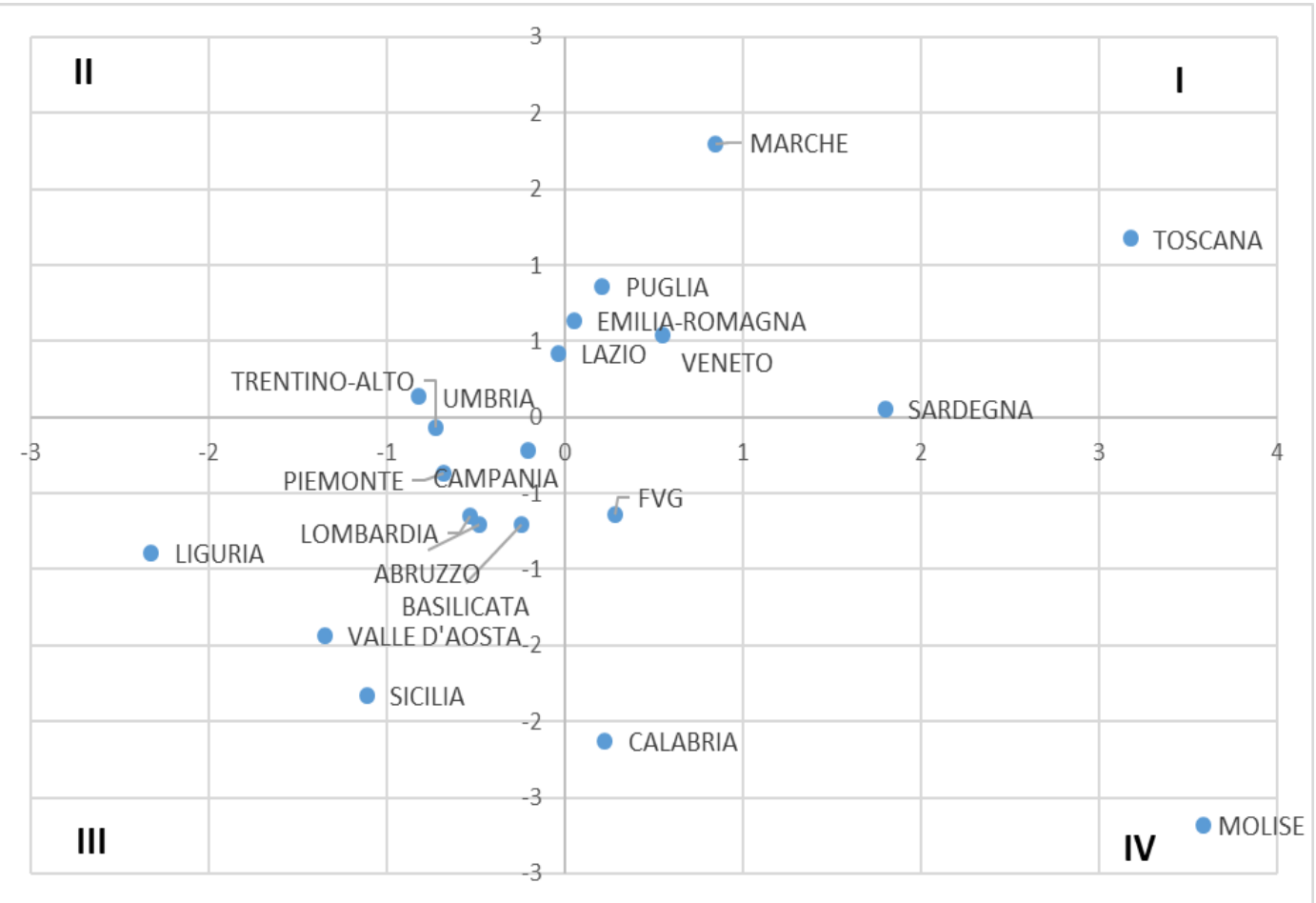

Source: Authors' own elaboration based on Bureau Van Dijk Data (2017). 
The scatterplot highlights in quarter I the regions with the highest values of indicators during and after the shock. Tuscany, with some big and solid enterprises emerges as the best TPS in terms of resilience followed by the Adriatic area (Marche and Apulia) characterized by productive network systems; EmiliaRomagna and Veneto, where policies for innovation, technology transfer, entrepreneurial networking and financial incentives compensate the small size of local units result as well positioned. Indeed, Emilia-Romagna and Veneto are traditionally vocated to machine manufacturing and equipment: the development of the Smart Manufacturing Cluster in the city of Piacenza can be taken as an example. The productive system of Lombardy (positioned in quarter III) doesn't reveal a good performance though the presence of a market-oriented business model. It marks a negative value of $\beta$ both in the recession phase and in recovery phase, even if only slightly worse than the national level. Quarter IV shows the results of regions marking a value of $\beta$ greater than the national level during the crisis but smaller than the national level after the shock. It's the case of Friuli Venezia Giulia that constitutes an important share of the Italian machine manufacturing sector. These main evidences induce the Authors to continue the research through the investigation of the reasons below the placement. The review of the literature on the themes of organizational and territorial resilience and the descriptive analysis conducted on the performance of TPSs in machine manufacturing and equipment suggest some hypotheses to be tested to understand the effects of territorial (TFs) and/or organizational factors (OFs) such as:

$H 1_{(T F)}$ : existence of policies for innovation, entrepreneurial networking and financial incentives

$H 2_{(T F)}$ : presence of leaders of the sectors

$H 3_{(T F)}$ : connection with the innovation systems, technological transfer

$H 4_{(T F)}$ : importance of the sector in the economic base of the local systems

$H 5_{(O F)}$ : flexible macro organizational structure and assets (robust, redundant, resourceful)

$H 6_{(O F)}$ : specific micro organizational features, promoting resilience via HR strategic management

$H 7_{(O F)}$ : ability to learn from past experience

$H 8_{(O F)}$ : ability to act in a preemptive and proactive way

These are only some of the hypothesis the Authors would like to test. During the research, some others will be certainly added. This list is not exhaustive but only representative of the qualitative survey that will follow the conclusion of this quantitative part.

\section{Future Work}

As previously mentioned, the results of the quantitative survey encourage Authors to understand the reasons for the placement of TPSs in different quadrants. In this regard, it is fundamental to investigate which factors (company-related or territorial-related) have contributed to the positioning within a specific quadrant of 
the matrix. A questionnaire/interview containing references related to the hypotheses above formulated will be proposed to some enterprises inside a TPS featuring special or unexpected performances. The extraction will be rational and carried out according to the placement of the resistance/ recovery indexes and maybe to companies came out from a pre-insolvency creditor arrangement.

\section{Bibliography}

Bailey, D., \& Turok, I. (2016). Editorial. Resilience Revisited. Regional Studies, 50(4), 557-560. http://dx.doi.org/10.1080/00343404.2016.1146478

Bell, M. A. (2002). The Five Principles of Organizational Resilience. Gartner Research. Available at: http://home.trginc.com/sites/default/files/The\%20Five\%20Principles $\% 20$ of $\% 20$ Organizational $\% 2$ OResilience.pdf [24 October 2014].

Brondoni, S. M., \& Zaninotto E. (2018). Ouverture de 'The 4th Industrial Revolution. Business Model Innovation \& Global Competition'. Symphonya. Emerging Issues in Management (symphonya.unimib.it), (2), 1-7.

http://dx.doi.org/10.4468/2018.2.01ouverture

Büchi, G., Cugno, M., Castagnoli, R. (2018). Economies of Scale and Network Economies in Industry 4.0. Symphonya. Emerging Issues in Management (symphonya.unimib.it), (2), 66-76.

http://dx.doi.org/10.4468/2018.2.06buchi.cugno.castagnoli

Burton, R. M., \& Obel, B. (1988). Opportunism, Incentives, and the M-Iorm Hypothesis: A Laboratory Study. Journal of Economic Behavior \& Organization, 10 (1), 99-119.

Crichton, M. T., Ramsay, C.G., Kelly, T. (2009), Enhancing Organizational Resilience Through Emergency Planning: Learnings from Cross-Sectoral Lessons. Journal of Contingencies and Crisis Management, 17, 24-37.

http://dx.doi:10.1111/j.1468-5973.2009.00556.x

Dallara, A., \& Rizzi, P. (2012). A Geographic Map of Sustainability in the Italian Local Systems. Regional Studies, 46(3), 321-337.

http://dx.doi.org/10.1080/00343404.2010.504703

Foster, K.A. (2007). A Case Study Approach to Understanding Regional Resilience. Working paper 2007-08, Institute of Urban and Regional Development, Berkeley.

Gaio, L., Rossi, A., Zaninotto, E. (2018). Growth Through Metamorphosing. Symphonya. Emerging Issues in Management (symphonya.unimib.it), (2), 21-37.

http://dx.doi.org/10.4468/2018.2.03gaio.rossi.zaninotto

Giustiniano, L. \& Cantoni, F. (2017). Between Sponge and Titanium: Designing Micro and Macro Features for the Resilient Organization, in Boccardelli, P., Annosi, M. C., Brunetta, F., \& Magnusson, M. (eds.), Learning and Innovation in Hybrid Organizations. Basingstoke, UK: Palgrave Macmillan.

Graziano, P., Rizzi, P., Barbieri, L., Piva, C. (2019). A Regional Analysis of Wellbeing and Resilience Capacity in Europe. Scienze Regionali, 18, 551-574.

Graziano, P., \& Rizzi, P. (2016). Vulnerability and Resilience in the Local Systems: The Case of Italian Provinces. Science of the Total Environment, 553, 211-222.

http://dx.doi.org/10.1016/j.scitotenv.2016.02.051

Hamel, G., \& Valikangas, L. (2003). The Quest for Resilience. Harvard Business Review, 81(9), 5265.

Kendra, J. M., \& Wachtendorf, T. (2003). Elements of Resilience After the World Trade Center Disaster: Reconstituting New York City's Emergency Operations Center. Disasters, 27(1), 37-53. http://dx.doi.org/10.1111/1467-7717.00218 
Lengnick-Hall, C. A., Beck T. E., Lengnick-Hall, M. L. (2011). Developing a Capacity for Organizational Resilience Through Strategic Human Resource Management. Human Resource Management Review, 21(3), 243-255.

http://dx.doi.org/10.1016/j.hrmr.2010.07.001

Mallak, L. A. (1998). Putting Organizational Resilience to Work. Industrial Management, 40(6), 8-13.

Mallak, L. A. (1997). How to Build a Resilient Organization, in Proceedings of the Industrial Engineering Solutions 1997 Conference, 170-177, Miami, May.

Marshall, A., \& Ojiako, U. (2010). From the Myth of Prometheus to Strategic Resilience: Two Cognitive Paradigms Linking Risk and Innovation. Prometheus, 28(4), 343-360.

http://dx.doi.org/10.1080/08109028.2010.539018

Martin, R. (2012). Regional Economic Resilience, Hysteresis and Recessionary Shocks. Journal of Economic Geography, 12(1), 1-32.

http://dx.doi.org/10.1093/jeg/lbr019

Martin, R. (2016). How Regions React to Recessions: Resilience and the Role of Economic Structure. Regional Studies, 50(4), 561-585.

http://dx.doi.org/10.1080/00343404.2015.1136410

Martin, R., \& Sunley, P. (2015). On the Notion of Regional Economic Resilience: Conceptualization and Explanation. Journal of Economic Geography, 15(1), 1-42.

http://dx.doi.org/10.1093/jeg/lbu015

Pironti, M., Pisano, P., Papa, A. (2018). Technology Resilience and the S.T.O.R.M. Factory. Symphonya. Emerging Issues in Management (symphonya.unimib.it), (2), 108-124.

http://dx.doi.org/10.4468/2018.2.09pironti.pisano.papa

Ponomarov, S. Y., \& Holcomb, M. C. (2009). Understanding the Concept of Supply Chain Resilience, The International Journal of Logistics Management, 20(1), 124-143.

http://dx.doi.org/10.1108/09574090910954873

Rizzi, P. (2018). Hybrid Innovation in Global Business Management, in Brondoni, S. M. (ed.), Competitive Business Management. A Global Perspective. New York \& Turin: Routledge \& Giappichelli.

Rizzi, P., Campanini, F., Costa, S. (2012). Hybrid Innovation: The Case of the Italian Machine Tool Industry. Symphonya. Emerging Issues in Management (symphonya.unimib.it), (1), 45-56.

http://dx.doi.org/10.4468/2012.1.04rizzi.campanini.costa

Rizzi, P., \& Graziano, P. (2017). Regional Perspective on Tourism Global Trend. Symphonya. Emerging Issues in Management (symphonya.unimib.it), Special Issue: Global Tourism Management, 11-26.

http://dx.doi.org/10.4468/2017.3.02rizzi.graziano

Rizzi, P., Graziano, P., Dallara, A. (2017). A Capacity Approach to Territorial Resilience: The Case of European Regions. The Annals of Regional Science, 60, 285-328.

http://dx.doi.org/10.1007/s00168-017-0854-1

Sheffi, Y. (2005). The Resilient Enterprise: Overcoming Vulnerability for Competitive Advantage. MIT Press Books: Cambridge, MA.

Somers, S. (2009). Measuring Resilience Potential: An Adaptive Strategy for Organizational Crisis Planning. Journal of Contingencies and Crisis Management, 17, 12-23.

http://dx.doi.org/10.1111/j.1468-5973.2009.00558.x

Sutcliffe, K. M., \& Vogus, T. J. (2003). Organizing for Resilience, in Cameron, K., Dutton J. E., \& Quinn R. E. (eds), Positive Organizational Scholarship: Foundations of a New Discipline. San Francisco, CA: Berrett-Koeler Publishers.

Vale, L. J., \& Campanella, T. J. (2005). The Resilient City. Oxford University Press, New York

Vogus, T. J., \& Sutcliffe, K. M. (2007). Organizational Resilience: Towards a Theory and Research Agenda. Systems, Man and Cybernetics, ISIC. IEEE International Conference, 3418-3422.

Walker, B., Holling, C. S., Carpenter, S. R., \& Kinzig, A. (2004). Resilience, Adaptability and Transformability in Social-Ecological Systems. Ecology and Society, 9(2), 5. 
World Bank (2014) World Development Report 2014: Risk and Opportunity - Managing Risk for Development. Washington.

\begin{abstract}
Notes
${ }^{1}$ The 2016 financial year (for those who have an accounting exercise coinciding with the calendar year) is the first annual financial statement drawn up with the changes introduced by the transposition into our system (thanks to Italian Legislative Decree 139/2015), of the UE Accounting Directive 34/2013/EU. Following the changes introduced by the aforementioned Legislative Decree, the Italian Accounting standards have been updated accordingly; in this case, the Italian Accounting standards OIC 12 "Composition and financial statements", has undergone the necessary updating, given that Legislative Decree modified the balance sheet and the profit and loss account schemes, intervening on articles 2424 and 2425 of the Civil Code. Among the changes made to the profit and loss account, is particularly important the elimination of the extraordinary section (Class of Item "E) Non-operating Revenues and Expenses"), where the Extraordinary (or Not-Operating) Revenues and Expenses were found. Thanks to this change (which came into force in the 2016 financial statements), the aforementioned cases must therefore be reclassified as part of the other cost and revenue items, with a clear impact on the Operating Result. Obviously this approach will bring "differences" in the comparison of financial statements over time, especially over a long period of time as we have done; this could create differences (for example) between the operating results of 2015 and 2016 caused not only by the obvious variations dictated by the management, but also by the different classification of the extraordinary area results and then cause problems of comparative analysis. This led us to decide to exclude the aforementioned 2016 financial statements from our analysis.

2 This is valid for the annual financial statements prepared up to 2015, as from 2016 the Class of Item "E) Non-Operating Revenues and Expenses" in the profit and loss account, appointed to accept the Extraordinary (or Not-Operating) Revenues and Expenses, does not exist anymore and the relative values have been reclassified in Class of Item A "Value of Production" and B "Cost of Production" of the Profit and Loss account.
\end{abstract}

